\title{
Study on Preparation of Flexible Semiconductor Electrode for Dye-sensitized Solar Cells by EPD
}

\author{
W.T. Chiang", P.T. Lee, R.Q. Hsu \\ Department of Mechanical Engineering, National Chiao Tung University, Taiwan
}

Copyright (C) 2015 by authors, all rights reserved. Authors agree that this article remains permanently open access under the terms of the Creative Commons Attribution License 4.0 International License

\begin{abstract}
In recent years, the development of DSSC produced considerable research interest, including improving efficiency, packaging and flexible possibilities. Flexible possibility has great potential for all kinds of applications. Researches on the bendability of the solar cell thin sheets are mostly focus on the making the soft substrate or electrodes. Previous studies showed that coating method of $\mathrm{TiO}_{2}$ semiconductor electrodes cracked after bending. This phenomenon makes the DSSC efficiency and lifetime substantially decline. The electrophoretic deposition (EPD) technique with a wide range of novel applications in the processing of advanced materials and coatings, has recently gained increasing interest both in academia and industrial sector not only because of the high versatility of its use with different materials and their combinations but also because of its cost-effectiveness requiring simple apparatus. This study used a flexible conductive material (ITO-PEN) as substrate. The semiconductor electrode was prepared by eletrophoresis deposition (EPD) method. After bending test, we observe the morphology and electrical properties of semiconductor electrodes. The photocurrent-voltage characteristics of assembled the DSSC were measured by Luzchem Solar Simulator (standard AM 1.5). Results of flexible DSSC indicated that feature enables the flexible solar cells after bending to avoid fragmentation of semiconductor electrodes, and the efficiency doesn't decrease.
\end{abstract}

\section{Keywords Dye-sensitized Solar Cells (DSSC), Electrophoretic Deposition (EPD), Flexible DSSC, Bendability of DSSC}

\section{Introduction}

With increasing human population and energy consumption, it is obvious that we need to find alternative sources of energy. At the beginning of the 21 st century, different kinds of traditional petrochemical energy are getting dried up day by day, such as coal, fuel, natural gas, creating serious pollution to environment. Therefore, different countries start to pay attention to the development of renewable energy. Solar cells are able to convert light directly into electricity by photovoltaic effect. With solar cells, some energy loss caused by complicated process of energy conversion can be avoided. Nowadays, solar cells are divided into crystalline silicon solar cells, multi-crystalline silicon solar cells, dye-sensitized nanostructured solar cells and organic solar cells. The first two kinds of solar cells have high efficiency, extensive application, and use silicon, which is very abundant; but their application is limited by their high price. The last two kinds of solar cells are still at the development stage. Although organic semiconductor thin film solar cells are flexible and controllable, their efficiency is still quite low. In 1990 Gratzel published a paper about DSSC [1].

DSSC is a third generation thin film solar cell. It has the advantages of low material cost, easy fabrication process and simple fabrication equipment. The component structure of DSSC (Figure 1) is composed mainly of the glass substrate, transparent conductor (indium tin oxide, ITO), semiconductor material (titanium oxide), dye, electrolyte, and cathode $(\mathrm{Pt})$. However, due to the fragility and inflexibility of the glass substrate, its application is limited. If low-cost and highly efficient dye-sensitized solar cells can be developed, it will become an important new direction for the development of solar cells.

Dye-sensitized solar cells currently have three development challenges. (i) Efficiency, (ii) package and (iii) flexibility. First, efficiency is the largest number of research topics [2-8]. Most research is to develop dyes and $\mathrm{TiO}_{2}$ surface modification. In a Nature publication, Michael Grätzel's team at EPFL has developed a state solid version of the DSSC raising their efficiency up to a record $15 \%$. He is the founder of the DSSC. The modern version of a dye solar cell is also known as the Grätzel cell. Second, in dye-sensitized solar cells, generally using $\mathrm{KI}$ and $\mathrm{I}_{2}$ as a liquid electrolyte. Liquid electrolyte will have two problems: evaporation or leakage. Solid electrolyte is the focus of research for solving the problems of liquid electrolyte. Third, if a softer material could be used as the base material of 
DSSC, its flexible property could increase the potential development for DSSC [9-13]. Flexible DSSC was initially proposed by Pichot et al. [14], though it was not until 2005 that the stainless steel was proposed as the substrate for flexible DSSC [15]. Although similar studies were presented subsequently, it was not until 2009 that the substitution of stainless steel sheet by titanium (Ti) sheet was proposed to achieve higher photoelectric conversion efficiency [16].

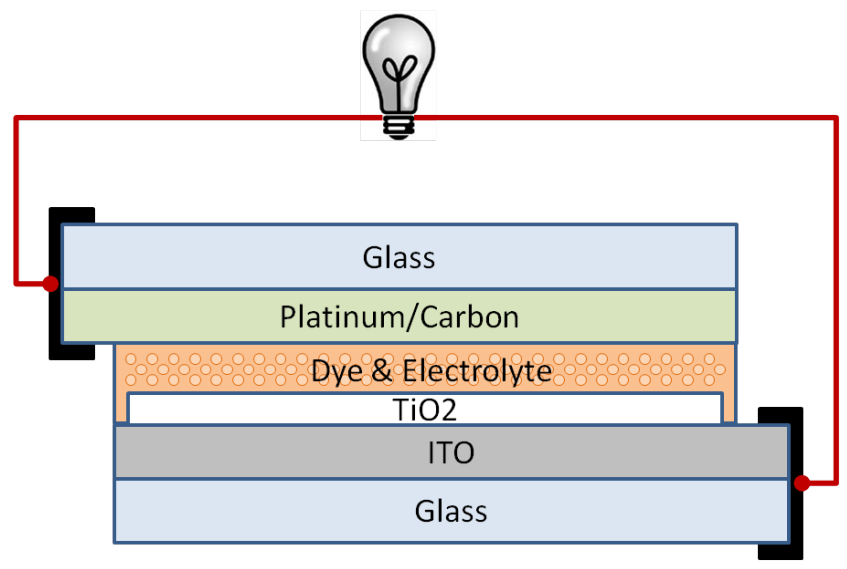

Figure 1. The component structure of DSSC

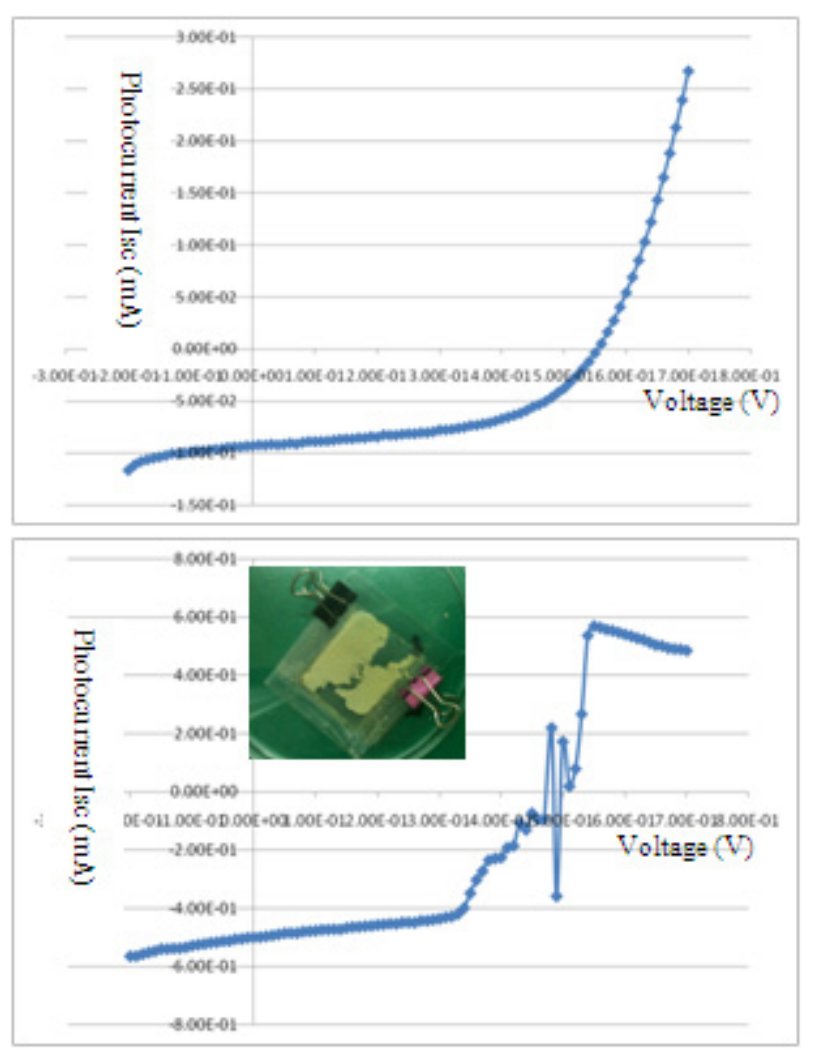

Figure 2. Traditional preparation before and after bending

Traditional preparation of $\mathrm{TiO}_{2}$ electrode has 3 methods [17]: doctor-blade, spin coating and screen printing. As the experimental results in Figure and I-V curve we can see (Figure 2), because of its thickness and adsorption force, electrode broken after several times banding. Our purpose of this study is that based on flexible transparent conductive substrate. Study on the semiconductor electrode prepared by the electrophoretic deposition (EPD) method, to increase lifetime of the DSSC after bending.

The electrophoretic deposition (EPD) technique with a wide range of novel applications in the processing of advanced materials and coatings, has recently gained increasing interest both in academia and industrial sector not only because of the high versatility of its use with different materials and their combinations but also because of its cost-effectiveness requiring simple apparatus. EPD has been known since 1808 when the Russian scientist Ruess observed an electric field induced movement of clay particles in water. But the first practical use of the techniques occurred in 1933 when the deposition of thoria particles on a platinum cathode as an emitter for electron tube application was patented in USA [18]. There can be two types of electrophoretic deposition depending on which electrode the deposition occurs (Figure 3). When the particles are positively charged, the deposition happens on the cathode and the process is called cathodic electrophoretic deposition. The deposition of negatively charged particles on positive electrode (anode) is termed as anodic electrophoretic deposition. By suitable modification of the surface charge on the particles, any of the two modes of deposition is possible. With regard to technological application the potential of EPD as a materials processing technique is being increasingly recognized by scientists and technologists. Some of the advantages of EPD include its low-cost, the fact that it is relatively fast and reproducible, and its potential for use in continuous processing. An organic surfactant-free process is another important advantage of EPD and the thickness, packing density or amount of colloids fabricated using EPD can be readily controlled by changing certain EPD parameters such as the electric field, concentration of electrolyte, and deposition time. a

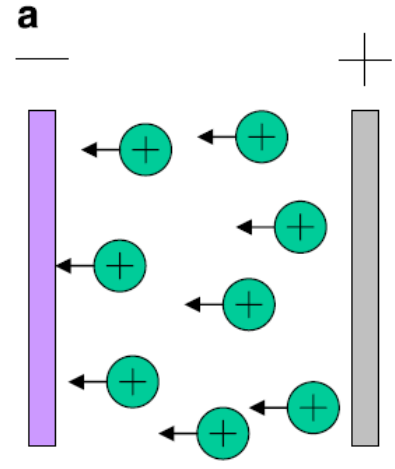

b

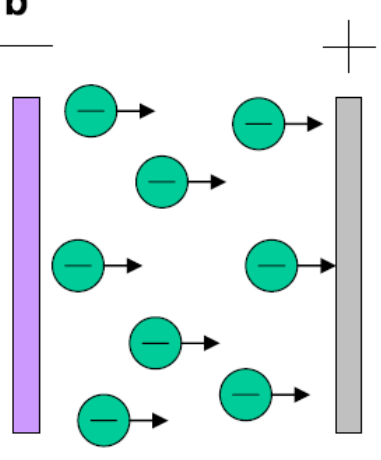

Figure 3. (a) Cathodic EPD and (b) anodic EPD.

In this study, we used a flexible conductive material (ITO-PEN) as substrate. The semiconductor electrode was prepared by eletrophoresis deposition method. The corresponding electrode was coated with platinum on ITO-PEN as electrode. Component parts were assembled between in two corresponding electrodes. Preparation by this process makes solar cells flexible. A bending test machine 
which can adjust the bending angle and frequency was designed to perform the test. After bending test, we observe the morphology and electrical properties of semiconductor electrodes.

\section{Experimental Procedure}

\subsection{Electrophoretic Deposition (EPD)}

PEN coated with indium tin oxide (ITO) was used as the substrate for creating the photoelectrode film of dye-sensitized solar cells with an active area of $25 \mathrm{~mm}^{2}$. A dispersion of nanocrystalline titanium oxide particles (P25, $20 \mathrm{~nm}$, Deguessa) with concentration of $0.25 \mathrm{~g} / \mathrm{L}$ in isopropyl alcohol (IPA, 99.5\%, Mallinckrodt) was used where $5 \times 10^{-5} \mathrm{M}$ magnesium nitrate hexahydrate (Aldrich, $99.995+\%$ ) and 2 vol.\% deionized water (DI water) were used as the electrolyte during the EPD process. A standard spacing of $2 \mathrm{~cm}$ was used between the ITO cathode and Nickel anode. These conditions were similarly used by Yum et al [19]. Nanocrystalline titanium oxide particle films were also created using a doctor blading method for comparison.

Various applied electric fields and deposition times were adopted to determine optimum conditions for creating nanocrystalline titanium oxide particle films for DSSC. Scanning Electron Microscopy (SEM) was employed to characterize the structure and morphology of the films. Cross-sections of the films were also viewed with the SEM to obtain thicknesses of the films so as to determine the optimum deposition time.

\subsection{Assembling of the Dye-sensitized Solar Cells}

DSSC were assembled using TCO electrodes (ITO-PEN, Rs $\approx 20 \Omega$ ) as substrates for both photo-electrode and counter-electrode. Counter-electrode were prepared by Platinum sputter coating onto the TCO substrate, yielding semitransparent Pt-based counter-electrode. For preparation of the photo-electrodes (active area of $0.25 \mathrm{~cm}^{2}$ ), an aliquot of a commercial $\mathrm{TiO}_{2}$ suspension was spread onto the $\mathrm{TCO}$ by the EPD or doctor blading technique. After drying in air for $5 \mathrm{~min}$, the electrodes were immersed in a $0.15 \mathrm{~m} \mathrm{~mol} \mathrm{~L}^{-1}$ solution of the sensitizer Di-tetrabutylammonium cis-bis(isothiocyanato)bis(2,2'-bipyridyl-4,4'-dicarboxylato )ruthenium(II) (N719, Solaronix) in acetonitrile for $18 \mathrm{~h}$.

After that, the electrodes were rinsed with ethanol and dried in air for $5 \mathrm{~min}$. The devices were sealed by Surlyn (Mitsui-Dupont Polychemicals) and the internal space was filled with the electrolyte solution. The electrolyte was composed of $0.6 \mathrm{M}$ tetrabutylammonium iodide, $0.1 \mathrm{M}$ lithium iodide, $0.1 \mathrm{M}$ iodine, and $0.5 \mathrm{M}$ 4-tert-butylpyridine in acetonitrile.

The solar cell performances were characterized while the samples were irradiated with AM 1.5 simulated sun light with the power density of $100 \mathrm{~mW} / \mathrm{cm}$.

\subsection{Bending Test}

That were used for packaging in a sandwich structure and this assembly was tested by bending machine. Bending test machine is developed for multiple and continuous bending under the same angle (Figure 4). A bending test machine which can adjust the bending angle and frequency was designed to perform the test. We set the angle was 30 degrees for 100 times as the standards for life-time test.

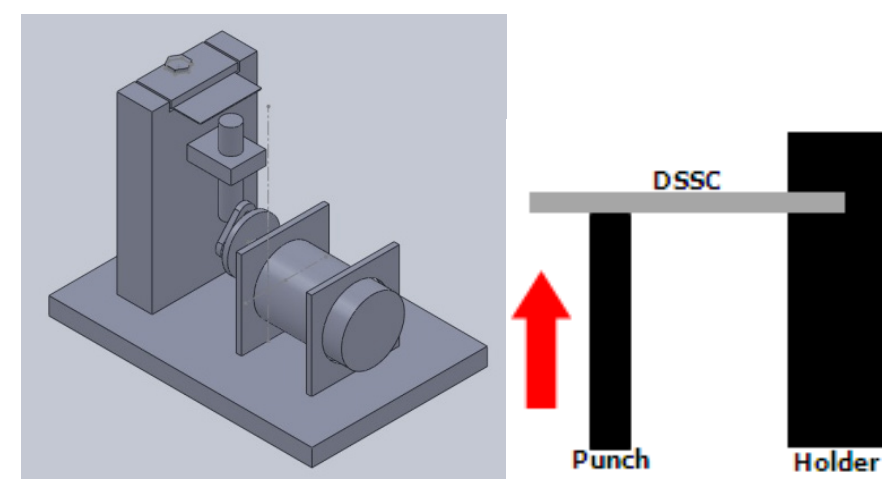

Figure 4. Illustration of bending test.

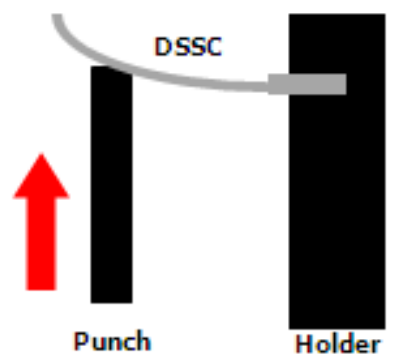




\section{Results and Discussions}

\subsection{Morphology Observation}

Using varying electric field intensities, different film morphologies were observed. As the electric field was increased, the film morphology became much denser. A rise in the electric field is met with an increase in the packing density of the film and a decrease in the EPD current, but the packing density is actually dependent on the EPD current as there is electrolysis of water at the cathode. A higher current results in more hydrolysis of water resulting in more evolution of hydrogen gas. The hydrogen gas evolution interrupts the deposition of the nanocrystalline titanium oxide particle and creates pores in the film. It was important to find a balance between internal surface area of the film and the ability of the dye to penetrate deep into the films pores. Too porous of a film results in low surface area and poor light absorption, while too dense of a film results in low penetration of the dye. During the experiments, we found that an excessive electric field causes ITO layer breakage. It was found a low electric field process $(5 \mathrm{~V} / \mathrm{cm})$ gave the desired film morphology without breakage.

Figure 5 shows the SEM cross-sectional views of semiconductor with EPD using deposition times of 5 to 30 interval five minutes. The thickness of $\mathrm{TiO}_{2}$ film was about 4 to 24 microns. Cross-sectional views of the nanocrystalline titanium oxide particle films revealed that deposition time under the same voltage proportional to the thickness. From the SEM images in Figure 6, it was found that too thick $\mathrm{TiO}_{2}$ layer will rupture after drying. It revealed the desired deposition time to be 15 minutes, leading to a film thickness of $12 \mu \mathrm{m}$.

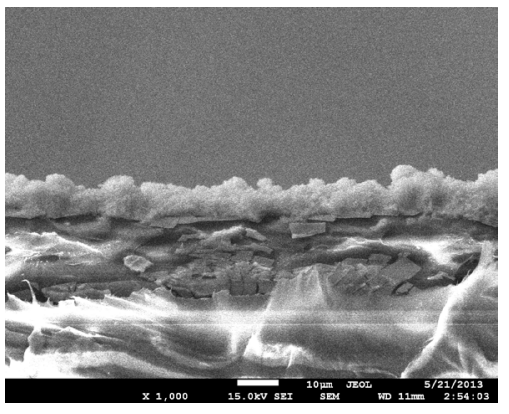

(a)

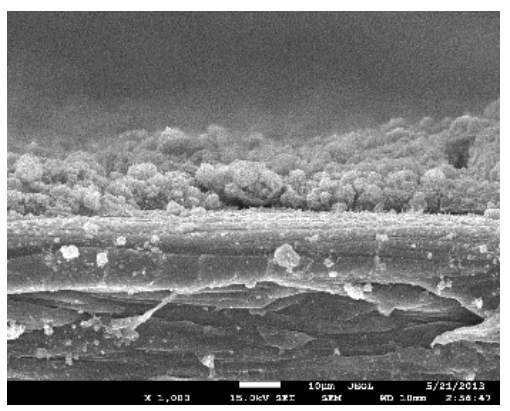

(d)

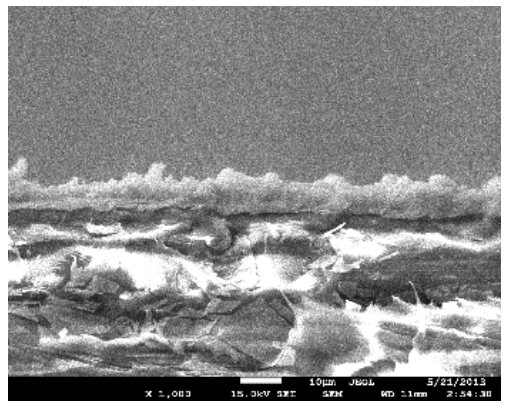

(b)

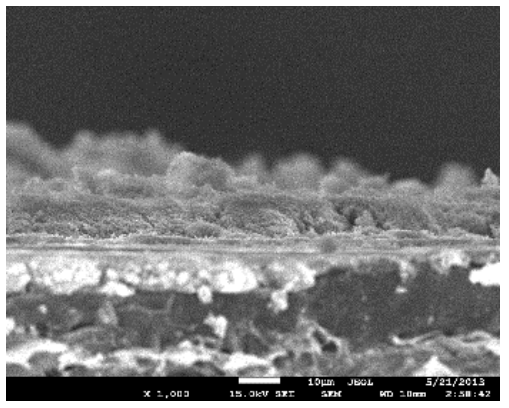

(e)

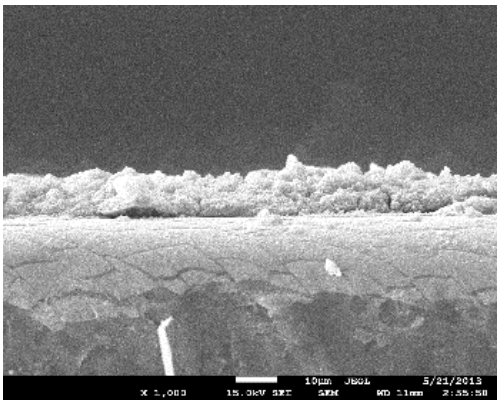

(c)

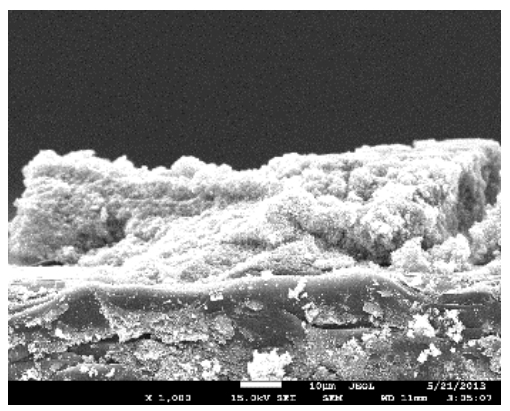

(f)

Figure 5. SEM cross-sectional views of semiconductor with EPD using deposition times of (a)5;(b)10;(c)15;(d)20;(e)25;(f)30 minutes. 


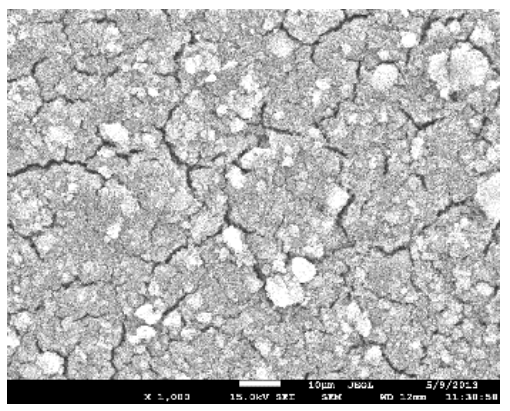

(a)

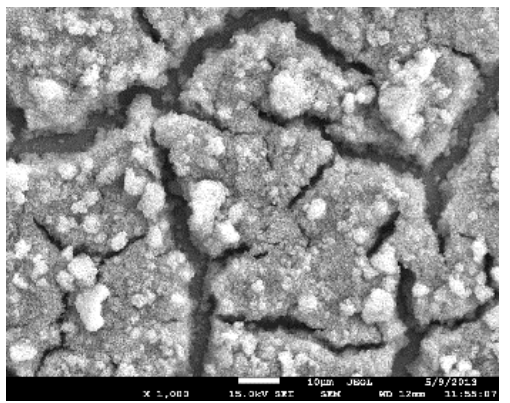

(d)

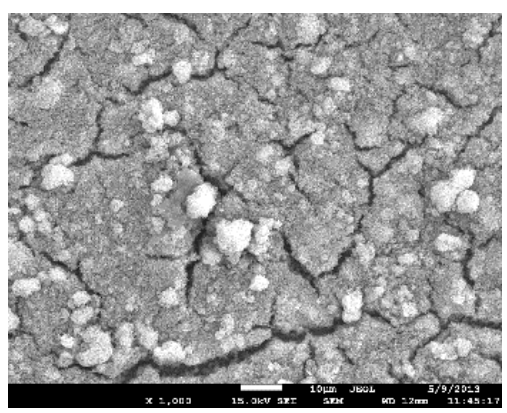

(b)

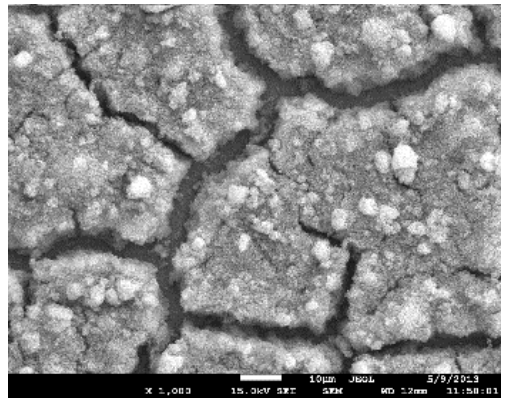

(e)

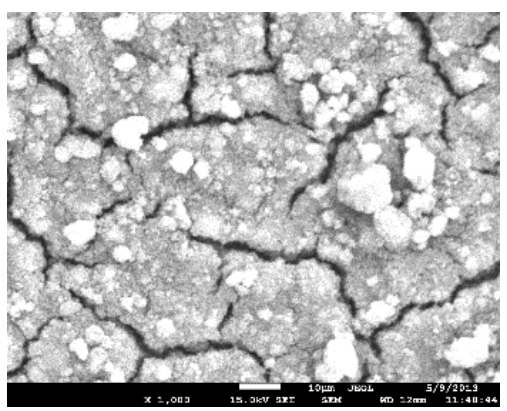

(c)

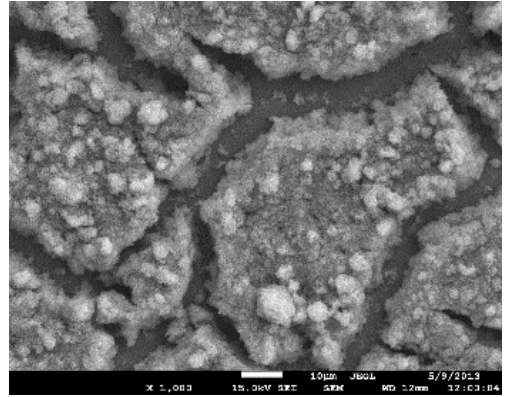

(f)

Figure 6. SEM top views of semiconductor with EPD using deposition times of (a)5;(b)10;(c)15;(d)20;(e)25;(f)30 minutes.

\subsection{Performance of DSSC}

Figure 7 shows the current-voltage curve of DSSC based on EPD process. Deposition time is 15 minutes. It indicates that performances of DSSC before and after bending 100 times. The open-circuit voltage (Voc) and short-circuit current densities (Jsc) of the DSSC decreases with increasing times of bending. The open-circuit voltage was from $760 \mathrm{mV}$ down to $680 \mathrm{mV}$, decreased about 11 percent. The short-circuit current densities was from $0.122 \mathrm{~mA} \mathrm{~cm}{ }^{-2}$ down to $0.029 \mathrm{~mA} \mathrm{~cm}^{-2}$, decreased about 77 percent. The photovoltaic performance decreased by 80 percent.

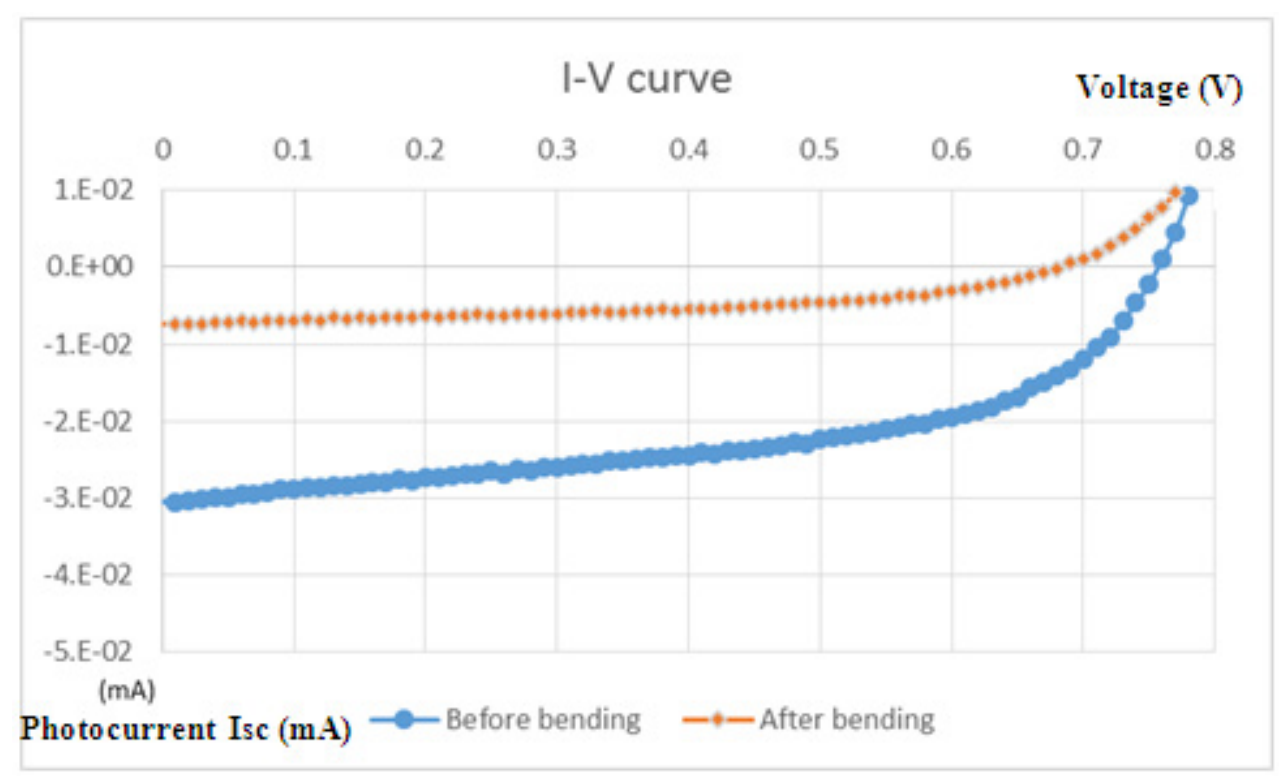

Figure 7. I-V curve of DSSC based on EPD process. Deposition time: 15 mins.

Figure 8 shows the current-voltage curve of DSSC based on traditonal process (doctor blading method). It indicates that performances of DSSC before and after bending 100 times. The open-circuit voltage (Voc) and short-circuit current densities (Jsc) of the DSSC decreases with increasing times of bending. The open-circuit voltage was from $630 \mathrm{mV}$ down to $490 \mathrm{mV}$, decreased about 23 percent. The short-circuit current densities was from $0.482 \mathrm{~mA} \mathrm{~cm}$ down to $0.056 \mathrm{~mA} \mathrm{~cm}^{-2}$, decreased about 89 percent. The photovoltaic performance decreased by 92 percent. 


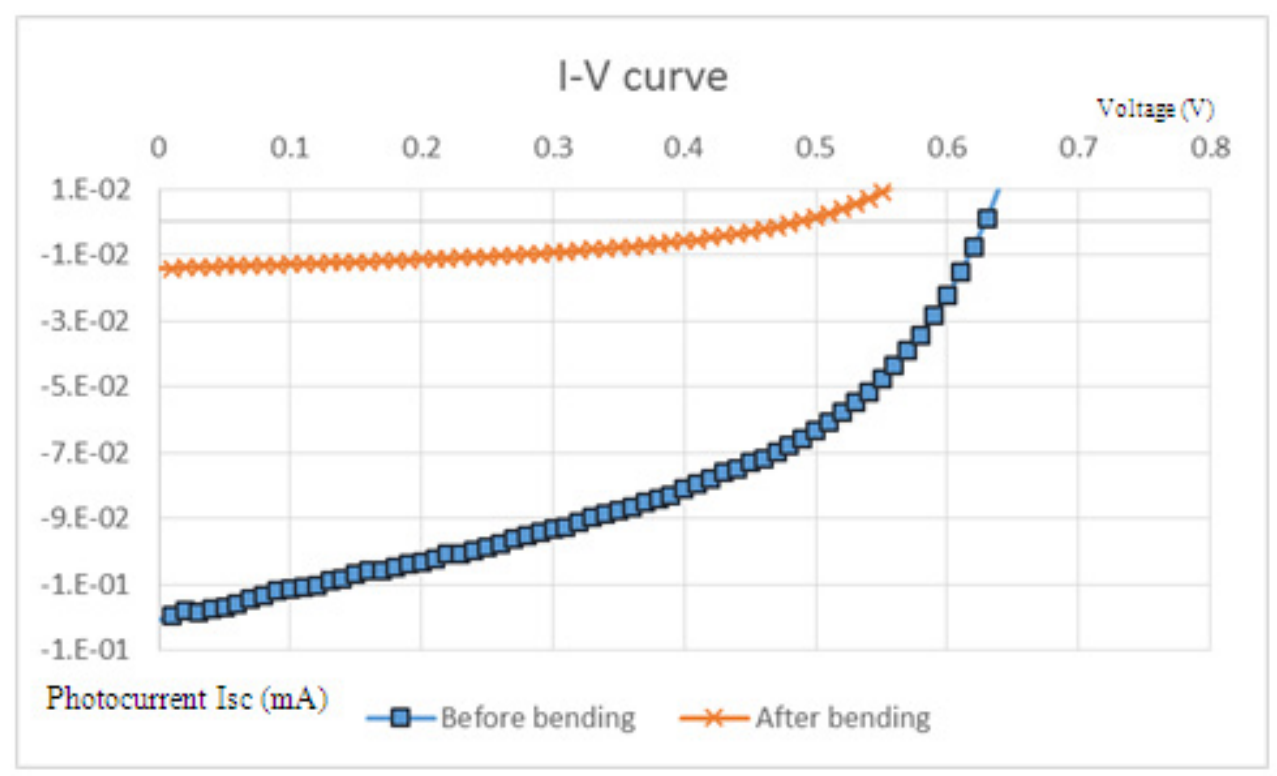

Figure 8. I-V curve of DSSC based on doctor blading method.

Table 1. Comparison of photovoltaic properties of the DSSC fabricated with different process.

\begin{tabular}{|c|c|c|c|c|c|}
\hline & & $\mathrm{J}_{\mathrm{sc}}\left(\mathrm{mA} / \mathrm{cm}^{2}\right)$ & $\mathrm{V}_{\mathrm{oc}}(\mathrm{mV})$ & $\mathrm{FF}(\%)$ & $\eta(\%)$ \\
\hline \multirow{2}{*}{ EPD process: deposition 15 mins. } & Before bending & 0.122 & 760 & 50.9 & 0.0473 \\
\cline { 2 - 7 } & After bending & 0.029 & 680 & 49.6 & 0.0099 \\
\hline \multirow{2}{*}{ Doctor blading method } & Before bending & 0.482 & 630 & 43.6 & 0.1327 \\
\cline { 2 - 7 } & After bending & 0.056 & 490 & 31.8 & 0.0087 \\
\hline
\end{tabular}

According to the results in Figure 7 and 8, we summarize the comparison of $\mathrm{Jsc}$, Voc, fill factor and conversion efficiency in the Table 1. After bending, fill factor of DSSC based on doctor blading method declined more than prepared by EPD process. The main impact of series resistance is to reduce the fill factor, although excessively high values may also reduce the short-circuit current. Therefore, we know that the destruction of the film will cause the series resistance increase.

\section{Conclusions}

1. General EPD working voltage was $20 \mathrm{~V}$ to $100 \mathrm{~V}$. We found that an excessive electric field causes ITO layer breakage. It was found a low electric field process $(5 \mathrm{~V} / \mathrm{cm})$ gave the desired film morphology without breakage.

2. EPD deposition time under the same voltage proportional to the thickness. Thickness can be obtained by controlling EPD parameters. But too thick $\mathrm{TiO}_{2}$ layer will rupture after drying.

3. After bending, the open-circuit voltage decreased and the short- circuit current decline. The semiconductor prepared by EPD process decreased less than by doctor blading method. The reason can be found by the visual observation. The $\mathrm{TiO}_{2}$ layer made by doctor blading has fallen off and broken after bending several times.

4. The short-circuit current densities dropped significantly because the resistance of $\mathrm{TiO}_{2}$ film has been enhanced after bending the cell. From Figure 7 and Table 1 we can see, after bending the electrodes that prepared by EPD do not destroy to cause fill factor decrease.

5. Previous studies about flexibility of DSSC rarely do the real bending test. In this research, we developed a test method for continuous bending under the same angle and speed.

\section{REFERENCES}

[1] B. Oregan and M. Gratzel, A Low-Cost, High-Efficiency Solar-Cell Based on Dye-Sensitized Colloidal $\mathrm{TiO}_{2}$ Films, Nature, 353, (1991), 737-740

[2] C. J. Barbe, F. Arendse, P. Comte, M. Jirousek, F. Lenzmann, V. Shklover and M. Gratzel, Nanocrystalline Titanium Oxide Electrodes for Photovoltaic Applications, Journal of the American Ceramic Society, 80(12), (1997), 3157-3171

[3] S. Ito, T. N. Murakami, P. Comte, P. Liska, C. Gratzel, M. K. Nazeeruddin and M. Gratzel, Fabrication of Thin Film Dye Sensitized Solar Cells with Solar to Electric Power Conversion Efficiency over 10\%, Thin Solid Films, 516(4), (2008), 4613-4619 
[4] D. B. Kuang, S. Ito, B. Wenger, C. Klein, J. E. Moser, R. Humphry-Baker, S. M. Zakeeruddin and M. Gratzel, High Molar Extinction Coefficient Heteroleptic Ruthenium Complexes for Thin Film Dye-Sensitized Solar Cells, Journal of the American Chemical Society, 128(12), (2006), 4146-4154

[5] T. P. Chou, Q. F. Zhang, G. E. Fryxell and G. Z. Cao, Hierarchically Structured ZnO Film for Dye-Sensitized Solar Cells with Enhanced Energy Conversion Efficiency, Advanced Materials, 19(18), (2007), 2588-2592

[6] Q. F. Zhang, T. R. Chou, B. Russo, S. A. Jenekhe and G. Z. Cao, Aggregation of $\mathrm{ZnO}$ Nanocrystallites for High Conversion Efficiency in Dye-Sensitized Solar Cells, Angewandte Chemie-International Edition, 47, (2008), 2402-2406

[7] Q. F. Zhang, C. S. Dandeneau, X. Y. Zhou and G. Z. Cao, ZnO Nanostructures for Dye-Sensitized Solar Cells, Advanced Materials, 21(41), (2009), 4087-4108

[8] Q. F. Zhang and G. Z. Cao, Nanostructured Photoelectrodes for Dye-Sensitized Solar Cells, Nano Today, 6(1), (2011), 91-109

[9] C. Y. Jiang, X. W. Sun, K. W. Tan, G. Q. Lo, A. K. K. Kyaw and D. L. Kwong, High-Bendability Flexible Dye-Sensitized Solar Cell with a Nanoparticle-Modified ZnO-Nanowire Electrode, Applied Physics Letters, 92(14), (2008), 143101

[10] D. Kuang, J. Brillet, P. Chen, M. Takata, S. Uchida, H. Miura, K. Sumioka, S. M. Zakeeruddin and M. Gratzel, Application of Highly Ordered $\mathrm{TiO}_{2}$ Nanotube Arrays in Flexible Dye-Sensitized Solar Cells, Acs Nano, 2, (2008), 1113-1116

[11] K. M. Lee, S. J. Wu, C. Y. Chen, C. G. Wu, M. Ikegami, K. Miyoshi, T. Miyasaka and K. C. Ho, Efficient and Stable Plastic Dye-Sensitized Solar Cells Based on a High Light-Harvesting Ruthenium Sensitizer, Journal of Materials
Chemistry, 19(28), (2009), 5009- 5015

[12] W. W. Tan, J. M. Chen, X. W. Zhou, J. B. Zhang, Y. A. Lin, X. P. Li and X. R. Xiao, Preparation of Nanocrys-talline TiO2 Thin Film at Low Temperature and Its Ap-plication in Dye-Sensitized Solar Cell, Journal of Solid State Electrochemistry, 13(5), (2009), 651-656

[13] H. C. Weerasinghe, P. M. Sirimanne, G. V. Franks, G. P. Simon and Y. B. Cheng, Low Temperature Chemically Sintered Nano-Crystalline $\mathrm{TiO}_{2}$ Electrodes for Flexible Dye-Sensitized Solar Cells, Journal of Photochemistry and Photobiology A: Chemistry, 213(1), (2010), 30-36.

[14] F. Pichot, J.R. Pitts, B.A. Gregg, Low-Temperature Sintering of $\mathrm{TiO}_{2}$ Colloids: Application to Flexible Dye-Sensitized Solar Cells, Langmuir 16, (2000) 5626-5630

[15] M.G. Kang, N.-G. Park, K.S. Ryu, S.H. Chang, K.-J. Kim, A $4.2 \%$ efficient flexible dye-sensitized $\mathrm{TiO}_{2}$ solar cells using stainless steel substrate, Sol. Energy Mater. Sol. Cells 90, (2006) 574-581

[16] W. Tan, X. Yin, X. Zhou, J. Zhang, X. Xiao, Y. Lin, Electrophoretic deposition of nanocrystalline $\mathrm{TiO}_{2}$ films on Ti substrates for use in flexible dye-sensitized solar cells, Electrochim. Acta 54, (2009), 4467-4472.

[17] K. Hara, \& H. Arakawa, ,Dye-sensitized solar cells., Handbook of photovoltaic science and engineering, 6634696, (2003)

[18] L. Besra, \& M. Liu, ,A review on fundamentals and applications of electrophoretic deposition (EPD)., Progress in materials science, 52(1), (2007), 1-61

[19] J. H. Yum, S. S. Kim, D. Y. Kim and Y. E. Sung, Electrophoretically Deposited $\mathrm{TiO}_{2}$ Photo-Electrodes for Use in Flexible Dye-Sensitized Solar Cells, Journal of Photochemistry and Photobiology A: Chemistry, 173(1), (2005), 1-6 